\title{
Ciudad de Camagüey: un desafío para el uso del agua
}

\section{City of Camagüey: a challenge for the use of the water}

Recibido: junio 2020

Aceptado: febrero 2021

\section{Resumen}

Las ciudades han tenido que afrontar múltiples retos en la búsqueda de la preservación de su patrimonio construido, al ser uno de los actuales la contaminación y el aumento de enfermedades por el mal manejo del agua. Dos son los principales desafíos en materia de agua que afectan su sostenibilidad: la falta de acceso al agua saludable $\mathrm{y}$ al saneamiento y el aumento de desastres relacionados con el agua como inundaciones y sequías. Estos problemas impactan negativamente en la salud y el bienestar humano, la seguridad, el medio ambiente, el crecimiento económico y el desarrollo. La falta de servicios adecuados de suministro y saneamiento, conducen a enfermedades como la diarrea o brotes de malaria y de cólera. Siendo el objetivo de la investigación realizar una valoración analítica y retrospectiva por variables que influyen en la contaminación de las aguas y su repercusión en la salud de los moradores de la ciudad de Camagüey.

\section{Palabras Claves:}

Ciudad de Camagüey; agua; salud
Rosa González González ${ }^{1}$

\section{Keywords:}

City of Camagüey; water; health

\footnotetext{
1 Nacionalidad: cubana; adscripción: Universidad de Camagüey; Doctora en Ciencias Económicas; Profesora Titular de la Facultad de Construcciones; correo: rosa.gonzalez@reduc.edu.cu
} 


\section{INTRODUCCIÓN}

Para sus primeros asentamientos, el hombre buscó siempre las proximidades a sistemas fluviales, debido a la importancia del consumo del agua para la vida, y su empleo en las actividades económicas que comenzaron a practicar. Ejemplo de ello son, las primeras civilizaciones a orillas de los ríos Nilo, Tigris, Éufrates, Ganges y Yang Tsé. (Acosta, 2016)

Muchas ciudades, como Róterdam, Londres, Montreal, París, Nueva York, Buenos Aires, Shanghái, Tokio, Chicago o Hong Kong deben su riqueza, hoy en día, a la conexión con alguna gran vía de agua que favoreció su crecimiento y su prosperidad. Del mismo modo, áreas en las que el agua es muy escasa, como el norte de África o el Oriente Medio, han tenido históricamente dificultades de desarrollo. En la actualidad, los recursos naturales se han vuelto insuficientes con la creciente población mundial y su disposición, en varias regiones habitadas, es la preocupación de muchas organizaciones gubernamentales.

Es un reto para la humanidad, aprovechar este líquido vital que llega a la urbe, tanto por precipitaciones, como suministrado a través de sistemas de abastecimientos. Por lo que, se plantea que, la calidad del agua potable es una cuestión que preocupa a todos los países del mundo, tanto en desarrollo como desarrollados, por la importancia que tiene para la salud de la población. (Cuellar, 2017)

La salud y el bienestar humano, es el resultado de largos y complejos procesos sociales en que las condiciones de vida en la ciudad, unido a la cultura de sus habitantes, intervienen de manera importante y decisiva. Es por eso que la eliminación o disminución del riesgo de enfermar por contaminación de las aguas, debe abordarse desde un enfoque multidisciplinario, donde se conjuguen las variables demográficas, las culturales, el acceso a agua potable, al alcantarillado, al saneamiento, con las variables urbanas.

Según el Informe del Programa de Naciones Unidas para el Desarrollo (Programa, 2014), de los 4400 millones de habitantes del mundo en desarrollo casi el $60 \%$ carece de saneamiento básico y un tercio no tiene acceso al agua limpia. Las enfermedades de origen hídrico se encuentran entre las cinco primeras causas de muerte en los países de América Latina. Existe una relación directa entre estas cifras y los datos sobre cobertura y calidad del agua que consumen. Sólo el $24 \%$ de la población urbana de América Latina y el
Caribe dispone de algún tipo de sistema de vigilancia y control de la calidad del agua. (ONU, 2015)

En Cuba, la mortalidad por estas causas no son consideradas un problema, pero la morbilidad mantiene una tendencia ascendente, de ahí se deriva la importancia y necesidad vigente de su control y prevención. La ciudad de Camagüey, en los últimos años se ha visto afectada por las enfermedades de origen hídrico, principalmente el dengue. Esto se debe en gran medida, a la escasez y a los defectuosos sistemas de abasto y de saneamiento presente en las diferentes zonas de la urbe. (Ministerio, 2018)

Las ciudades, el agua y el hombre, constituyen tres partes dependientes e interrelacionadas entre sí, formando un sistema, donde cada una de ellas incide en el resto. El desarrollo de la ciudad de Camagüey ha estado acompañado de esa interacción. En ese proceso, la salud y el bienestar de las personas, en gran medida, es el resultado de cómo se ha manejado esa expansión, marcado por los diferentes matices de las etapas en que ha transcurrido hasta el día de hoy.

Al estudio de la evolución de la ciudad de Camagüey y del agua como elemento rector en su desarrollo, está dirigida la investigación. A partir de esto se traza el siguiente objetivo general: Realizar una valoración analítica y retrospectiva por variables que influyen en la contaminación de las aguas y su repercusión en la salud de los moradores de la ciudad de Camagüey. ${ }^{\circ}$

El método aplicado es sistémico, estructural, funcional para lograr un enfoque integral del análisis; elmétodode observación paralaobtención de las variables del entorno, utilizándose como apoyo el método de levantamiento topográfico; y el análisis de contenido se empleó para el procesamiento de la información disponible en documentos escritos como en otros tipos de textos, así como en edificios y redes; lo cual permitió buscar criterios acerca del desarrollo de la investigación y de los resultados obtenidos.

El aporte radica en realizar un estudio analítico y retrospectivo que permita vincular características del contexto, como desarrollo urbano, fuentes de contaminación, área de mayor incidencia de enfermedades y otros aspectos como las variables poblacionales de manera que el análisis sea integral y que dé paso a que los gestores del territorio como los gobiernos locales tengan una base para solucionar las incidencias detectadas. Su soporte está en diferentes estudios 
realizados por prestigiosos autores sobre la ciudad de Camagüey, que sirven como marco referencial y las valoraciones aportadas por los autores de la investigación a partir de los análisis visualizados por el diagnóstico realizado. Constituyendo la principal conclusión que, para trabajar en función del bienestar humano, al ser una variable importante el riesgo a enfermarse, el agua en las ciudades debe ser analizada en interrelación con el hombre, la urbanización y las consecuencias que trae su mal manejo para su salud, para así proponer acciones encaminadas a la paulatina recuperación de la calidad de este recurso.

\section{LA CIUDAD, EL HOMBRE Y EL AGUA}

El agua $\left(\mathrm{H}_{2} \mathrm{O}\right)$ es una sustancia cuya molécula está formada por dos átomos de hidrógeno y uno de oxígeno y es esencial para la supervivencia de todas las formas conocidas de vida. El término, generalmente se refiere a la sustancia en su estado líquido, aunque la misma puede hallarse en otros estados (Raffino, 2020). Siendo uno de los recursos no renovables, cuyo deterioro y contaminación se ha acrecentado durante los últimos años con preocupante velocidad.

Los recursos hídricos, tanto superficiales como subterráneos, cada vez resultan más escasos debido al aumento mundial de la población y a la intervención del ser humano en el ambiente, actividad que, contribuye a dañar su calidad. Los humanos llevan mucho tiempo depositando los residuos y basuras en la atmósfera, en la tierra y en el agua. Esta forma de actuar hace que los residuos no se traten adecuadamente y causen contaminación. La contaminación del agua afecta a las precipitaciones, a las aguas superficiales y a las subterráneas. (ONU, 2015)

Según la Organización Mundial de la Salud (Organización, 2014), el agua está contaminada cuando su composición se haya alterado de modo que no reúna las condiciones necesarias para ser utilizada beneficiosamente en el consumo del hombre y de los animales. Cuando la cantidad de contaminantes es excesiva, la autodepuración por los microorganismos descomponedores resulta imposible.

Se recomienda que en el agua para beber haya cero colonias de coliformes por $100 \mathrm{ml}$ de agua como buen índice para medir la salubridad de la misma. El 80\% de las enfermedades infecciosas y parasitarias, gastrointestinales y una tercera parte de las defunciones causadas por éstas, se deben al uso y consumo de agua contaminada; y también reconoce que solo un $41 \%$ de la población mundial consume agua tratada y desinfectada como para ser "segura". (Organización, 2014)

El análisis realizado al agua y su influencia en la ciudad, debe contemplar todas las interacciones de sus componentes, determinando los problemas fundamentales que provoca el mal uso de la infraestructura urbana en el riesgo a enfermarse de la población que la habita.

\section{Variable urbana}

La ciudad de Camagüey cabecera municipal, regional, y provincial, se localiza al sureste del municipio. Privilegios como su ubicación geográfica, su relevancia a nivel industrial y la existencia de los mayores servicios superiores de la provincia, la han convertido en una influencia sobre municipios, ciudades y asentamientos vecinos.

La villa, se encuentra enlazada al recurso agua en todo su desarrollo, nace y en solo 14 años, conoció tres asentamientos. El primero le dio su nombre: El Puerto del Príncipe. En el siglo XVI los colonizadores habían bautizado así a la actual bahía de Nuevitas, en la costa norte. En un punto al oeste del interior de la bahía fue fundada, de allí su nombre completo, que con el tiempo se reduciría a Puerto Príncipe, aun cuando se alejara poco a poco del mar y se retirara hacia los márgenes del Caonao, en busca de agua fresca, mejores tierras y pasto para el ganado, termina su peregrinar entre los ríos Tínima y Hatibonico (Torres, 1888), donde se encuentra actualmente establecida con el nombre de Camagüey (Ver Figura 1 p. 16). Su segunda y última ubicación cumple con las instrucciones del Consejo de Indias de construir la mayoría de las ciudades en el interior de los territorios, para garantizar el abastecimiento de agua.

En sus primeros años, las principales fuentes de suministro de agua eran los dos ríos y lagunas existentes, sin embargo la ciudad en la medida que creció invadió la franja de protección de ellos sobre todo la del Hatibonico, al tenerse que ensanchar, en 1861 y profundizar el cauce para, aminorar la elevación de las aguas en sus desbordadas crecientes. Actualmente este es uno de los puntos más críticos y que más impacta en las condiciones ambientales de toda su área, por las afectaciones por inundación al patrimonio habitacional, que trae aparejado. (Ver Figura 2 p. 16) 
Figura 1. Asentamientos de la ciudad de Camagüey

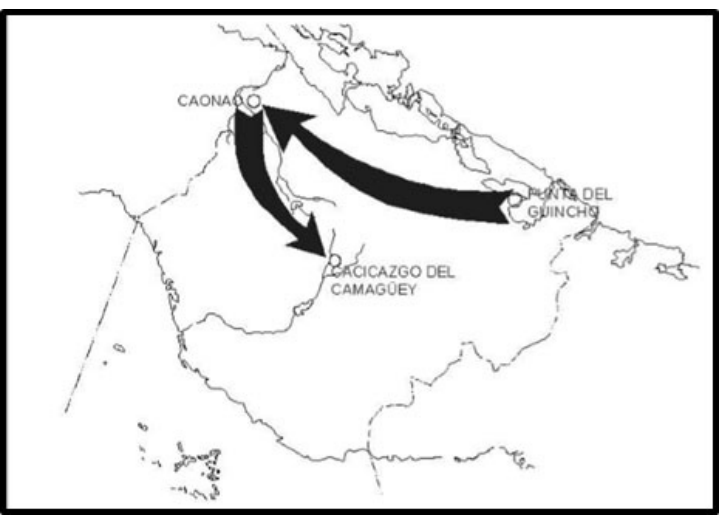

Fuente: Gómez, 2006

Figura 2. Invasión de la franja de protección de los ríos

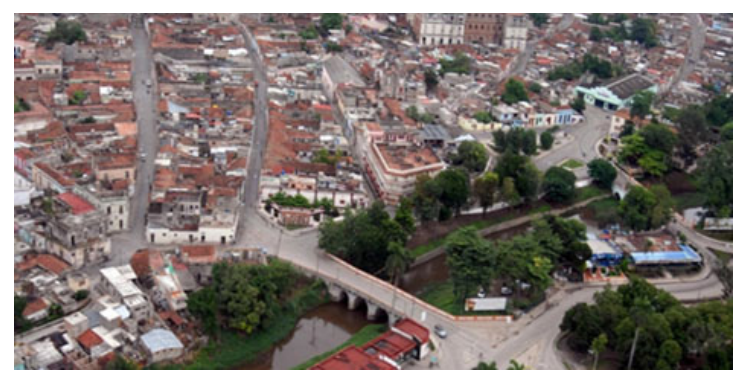

Fuente: Elaborado por los autores a partir de revisión bibliográfica

En el orden que creció la ciudad y su población, carente de alcantarillado y plagada de letrinas, iglesias donde se acostumbraba a realizar enterramientos, se inició la contaminación de las mismas (Torres, 1888), (Gómez, 2009), (Dirección, 2018). Esta aumentó cuando en 1814 se construye el Cementerio General, en un principio lejos del centro, pero que por su crecimiento mal gestionado, y los enterramientos realizados impactó tanto a las aguas subterráneas como superficiales, consecuencias que perduran en la ciudad de hoy en día. Además, se ejecutó la obra de un matadero en 1729 y de diferentes hospitales que practicaban el casi nulo tratamiento a las aguas servidas y su vertimiento directo al suelo y a los ríos, constituyendo, entre otras, los primeros contaminantes de las aguas subterráneas y de las fuentes de abasto de agua potable, que impactaron negativamente al área que ocupa hoy el centro histórico.

Luego de las Ordenanzas de Construcción de 1908 se vislumbran los lineamientos para uniformar la trama urbana, sin embargo a fines de la
República, el hábitat se extendió desordenadamente en ampliaciones de repartos existentes.

A partir de 1959, con la llegada de un nuevo sistema económico, político y social, comienza el planeamiento urbano. No obstante a este logro, la crisis económica del período especial en los '90 propició la expansión espontánea hacia zonas periféricas, incorporando áreas carentes de redes de infraestructura técnica, que construían letrinas y se abastecían de pozos, sin tener en cuenta regulaciones existentes para su edificación. (Ver Figura 3)

Figura 3. Comparación entre el crecimiento poblacional, la vivienda y el uso del agua

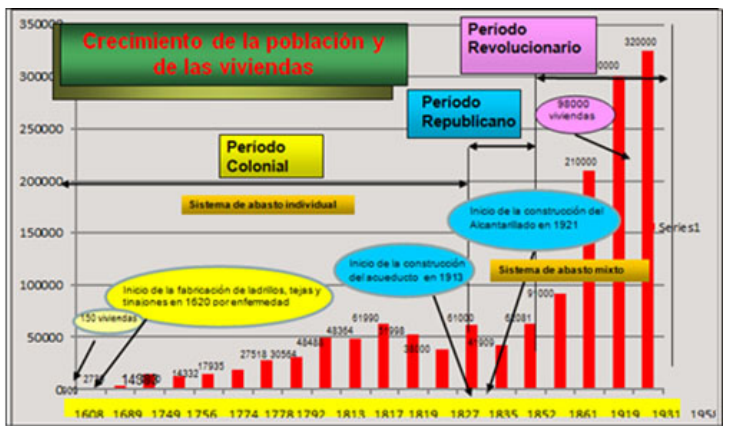

Fuente: Elaborado por los autores a partir de revisión bibliográfica

Paralelamente, el desarrollo urbano de la ciudad de Camagüey ha estado condicionado por los procesos sociales, económicos, culturales y naturales que se han sucedido en el transcurso de sus más de quinientos años de fundada, y que han quedado expresados en su estructura urbana. Expresado en una extensión de $63,21 \mathrm{~km}^{2} \mathrm{y}$ al observar su plano se aprecian cambios en la morfología urbana, que en algunos casos, como en la zona conocida como centro histórico, su trazado irregular se debió en gran medida para favorecer el escurrimiento del agua de lluvia hacia los ríos (González, 2014).

Se conoce, por datos de Planificación Física (Dirección, 2018), que en 1990 su área era de 5800 hectáreas (ha), ya para el 2002 se habían convertido en 6660 ha, y en el 2014 contaba con una superficie total de 8400 ha como límite, de los cuales, 6740 ha, cerca del $80 \%$, correspondían a área urbanizada; lo que evidencia un vertiginoso crecimiento urbano. En la actualidad, el 78\% del suelo de la ciudad es urbanizado, el 11.3\% corresponde al suelo propuesto como urbanizable y el $10.2 \%$ al no urbanizable. 
De los cuatro distritos en los que se divide: Cándido González, Joaquín de Agüero, Julio Antonio Mella e Ignacio Agramonte, el que posee mayor área es el Julio Antonio Mella con 2960,7ha; mientras que el más pequeño es el Cándido González con 585,14ha, el cual además presenta el mayor coeficiente de ocupación del suelo (COS) y el más negativo coeficiente de utilización de suelo (CUS), por predominar en el perfil urbano las edificaciones de poca altura. Por su parte, en los repartos Lenin de la Paz, Previsora, Puerto Príncipe, Julio Antonio Mella y el Microdistrito Ignacio Agramonte, hay un adecuado crecimiento en altura que condiciona una mejor utilización del suelo urbano en los tres restantes distritos.

En la ciudad, el principal uso de suelo es el residencial, representado por un total de 112 905 viviendas, de las que la mayoría pertenece al distrito Joaquín de Agüero. En el caso de los servicios básicos y medios, se encuentran mayoritariamente en Cándido González, distrito en el que se halla el centro histórico de la ciudad.
La mayor cantidad de edificaciones deportivas se encuentra en el distrito Julio A. Mella; las educacionales, predominan en Joaquín de Agüero; y las de salud (hospitales y consultorios del médico de la familia) en el Cándido González, aunque se distribuyen de una manera bastante uniforme en la ciudad.

Lo problemas mencionados con anterioridad persisten, la villa asumió el crecimiento posterior de la ciudad que se expandió a su alrededor; sumando las fuentes de contaminación existentes a nuevas, creadas por el desarrollo, primero en la República y posterior en el triunfo revolucionario. Por lo que se concluye que la principal fuente de contaminación es la ciudad de Camagüey, con una carga dispuesta expresada en la demanda bioquímica de oxigeno $\left(\mathrm{DBO}_{5}\right)$ que asciende a 4557 ton/año. Con 32 fuentes de contaminación dentro del perímetro urbano, de ellas 24 son industriales, seis son instalaciones de salud (hospitales), una es un centro de investigación y el otro es el asentamiento urbano. (Ver Figura 4)

Figura 4. Contaminación por industrias

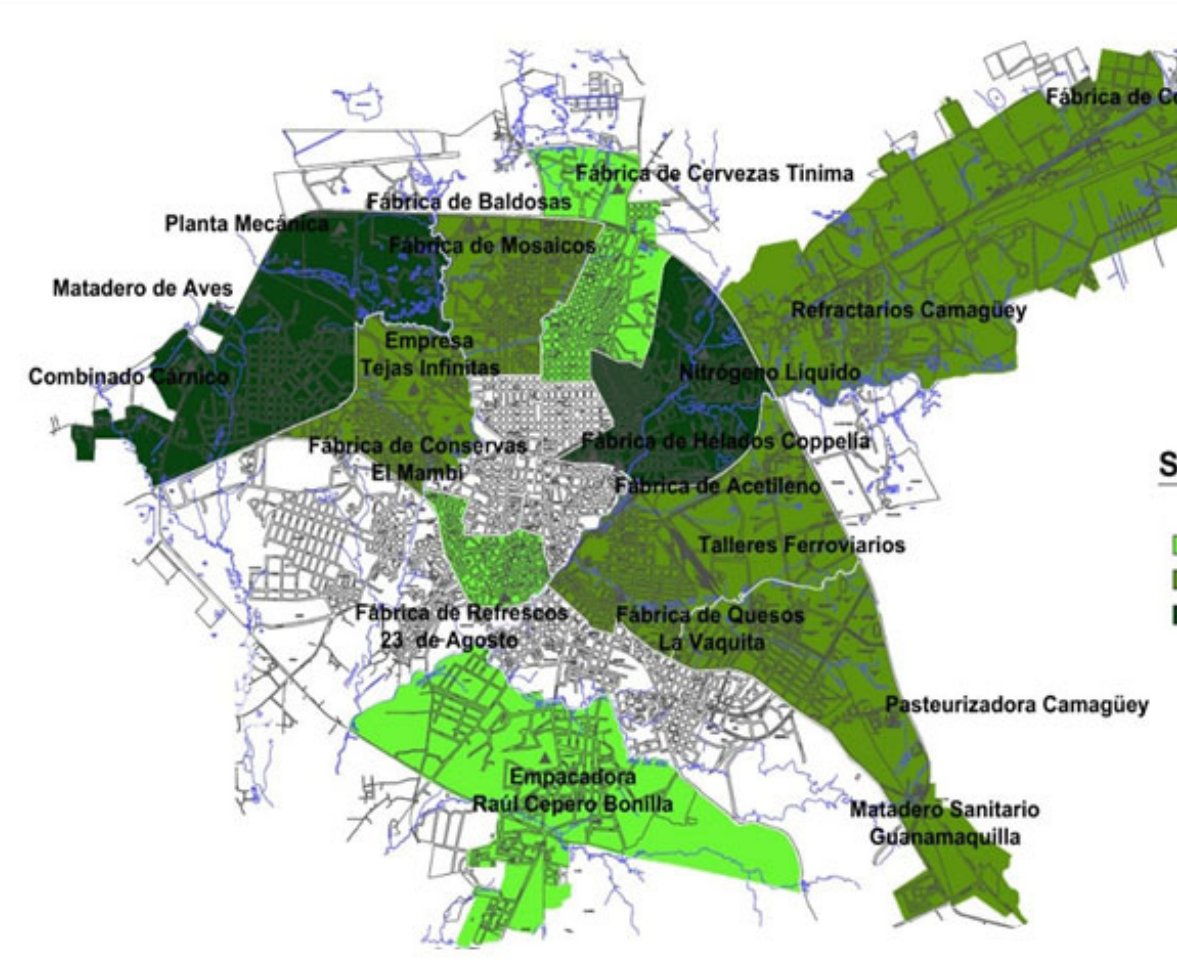

SIMBOLOGIA:

BAJO

MEDIO

ALTO

Fuente: Elaborado por los autores a partir de revisión bibliográfica 
Las ciudades no se pueden considerar sostenibles si no garantizan un acceso fiable al agua potable y un saneamiento adecuado. Lidiar con las necesidades crecientes de los servicios de agua y saneamiento es una de las cuestiones prioritarias de este siglo. La gestión sostenible, eficiente y equitativa del agua en las mismas no ha sido nunca tan importante como lo es en el panorama mundial actual. (ONU, 2015)

\section{Variable socio-cultural}

El proceso de desarrollo urbano camagüeyano es complejo (Ver Figura 5), en él se entrelazan los elementos de crecimiento poblacional, expansión de la villa y desarrollo de las infraestructuras. La ciudad fue variando y creciendo en el transcurso de los años, debido al crecimiento de su economía y el aumento de su población.

El incremento poblacional y de vivienda, no siempre estuvo acompañado de un desarrollo de infraestructuras que diera respuestas a las necesidades de esa evolución; muestra de ello es que aproximadamente 92 años después de 1528 , sus habitantes no estaban preparados para enfrentar aquellos retos que ya le imponía el entorno desde la perspectiva del agua y tuvieron que arreglárselas buscando nuevas soluciones con los recursos naturales locales que poseían.

Para la segunda mitad del siglo XIX existían 544 manzanas; 3953 casas y 1515 cuartos que hacen un total de 5468 edificios (Torres, 1888). A principio del siglo XX como respuesta al desarrollo económico de la región, inicia el desarrollo de su estructura urbana con la creación de numerosos asentamientos. El progreso económico estuvo acompañado del crecimiento demográfico. Posteriormente, la población fue creciendo a consecuencias del aumento vegetativo y migraciones intermunicipales y provinciales. Aunque se ha modificado paulatinamente su categoría migratoria, pasando de una situación de fuerte receptor durante los años de 1980 - 1995, a una débil recepción en el período de 1996 - 2002, en el contexto de las migraciones interprovinciales. Esto no significa que haya disminuido la notable atracción que ejerce la ciudad sobre las migraciones internas. Desde su fundación se ha sostenido como centro de mayor concentración de población de la región.

Figura 5. Desarollo urbano de la ciudad de Camagüey

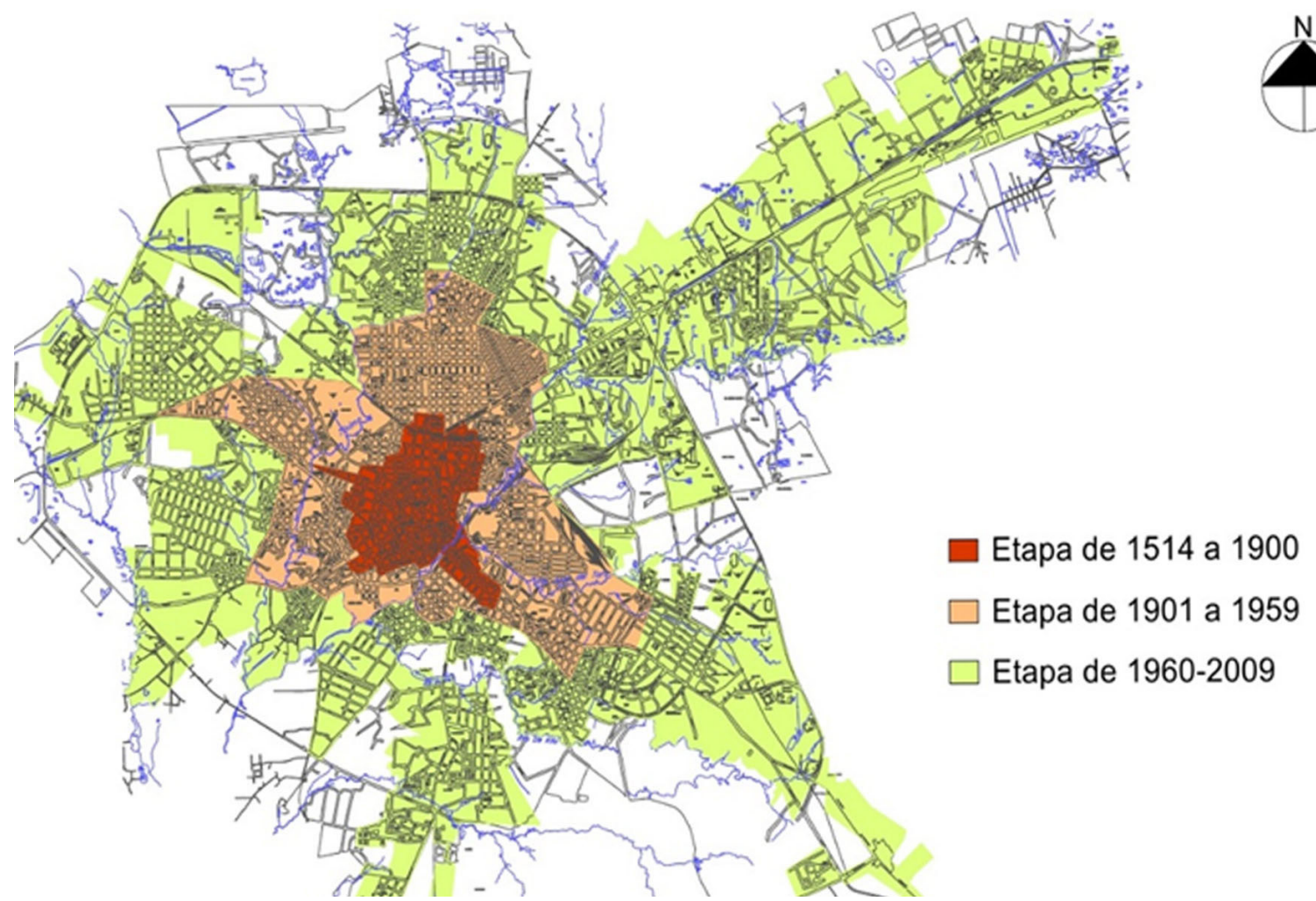

Fuente: Elaborado por los autores a partir de revisión bibliográfica 
Según último censo realizado, los 304268 habitantes de la ciudad representan el $95 \%$ de la población del municipio y el $39 \%$ de la población total de la provincia. Su distribución es uniforme en la mayor parte de las áreas de salud con más de 30000 habitantes cada una, excepto el Agramonte al que solo pertenecen 18860. Hay mayor cantidad de mujeres por área de salud, a excepción de la Oeste, para un total de 157289 mujeres y 146979 hombres a nivel de ciudad. El índice de habitabilidad se enmarca en el rango entre 2.61 en Centro hasta 2.87 en el Oeste, con un promedio a nivel de ciudad de 2.7 habitantes por vivienda. (Oficina, 2013)

Lo anterior ha influido en la morbilidad, debido a en primer lugar a que los ancianos, son más susceptible a enfermar, al encontrarse esta variable muy relacionada con las condiciones de habitabilidad y salubridad de la urbanizaciones.

\section{Variable agua}

Es inconcebible la planificación y desarrollo de un territorio ajeno a la gestión de las aguas; la experiencia universal ha demostrado que han de verse integradas la exploración de sus fuentes, su explotación, suministro, saneamiento y costos: "los recursos hídricos no son solamente las aguas limpias de precipitaciones, las almacenadas en reservorios, o las que fluyen como corrientes naturales, cercanas y al alcance inmediato del hombre; sino también las aguas de retorno, las aguas contaminadas...". (Mateo, 2015)

A escala urbana el agua puede dividirse en tres variantes: agua potable, aguas residuales (aguas negras y aguas grises) y agua de lluvia o pluvial. La primera, aunque significa apta para el consumo, responde a rasgos generales a la que es utilizada para la higiene personal y doméstica, beber y cocinar; la segunda se divide en negras, cuando proviene del inodoro, y grises, cuando son residuales menos contaminadas por las actividades de baño, lavado y fregado; y la tercera, como su nombre indica, es la que se obtiene mediante precipitación. (ONU, 2015)

La ciudad recibe el agua, la usa y la entrega al medio natural por diferentes formas, en ese contexto existen tres procesos importantes que se diferencian entre sí y que están estrechamente relacionados (Ecofluido, 2017):

Primer grupo: Abarca aquella parte del agua que llega a la ciudad por diferentes vías, también la que cae desde la atmósfera, pero que se usa a través de diferentes formas o sistemas de captación (redes de acueductos, sistemas de colección o captación desde los techos, pozos, tiendas y pipas).

Segundo grupo: Aborda aquella agua consumida (aguas grises) que se suministra al medio natural. En una ciudad con deficiente redes de acueducto y alcantarillado, sin sistemas de tratamiento de residuales, donde el agua contaminada por su uso doméstico o industrial se vierte directamente a los ríos o al manto freático, constituye una amenaza para la salud de las personas. A este grupo se le debe prestar mayor atención a la hora de invertir por el impacto que ocasiona en los ecosistemas y en la salud del hombre, además porque influye en el tercer grupo.

Tercer grupo: Caracteriza a aquella parte del agua que no se consume en el primer grupo y que se infiltra hacia el manto. En una ciudad con las mismas características descritas en el segundo grupo, también se contamina aumentando el riego de enfermar.

Este movimiento de las aguas descritas en los tres grupos anteriores, unido a la trayectoria caracterizada por la evaporación, la evapotranspiración, la condensación y por último la precipitación, en su interrelación con el desarrollo de la ciudad, servirá de referencia para los análisis posteriores.

Los recursos hídricos en Cuba no son abundantes, por lo que se requiere de un uso cada vez más racional. Tanto los disponibles como los aprovechables del país, son desiguales a todo lo largo y ancho del mismo, trayendo como consecuencia que de manera sistemática existan provincias que tengan déficit de agua para su desarrollo socioeconómico, como es el caso de Camagüey.

Durante el periodo colonial el abastecimiento de agua a la ciudad, tuvo sus particularidades; inicialmente sus habitantes tomaban el agua directamente de los ríos Hatibonico, pero sobre todo del Tínima y de las lagunas existentes; paralelamente o después, se realizaron algunos pozos, cuya cantidad fue elevándose en la medida que la villa aumentó su tamaño y la población creció demandando mayor cantidad de agua para su consumo y para los animales que criaban; más tarde, aprovechando la calidad de la arcilla cercana se construyeron los tinajones; la fabricación de los mismos alcanzó tal magnitud que a inicio del siglo XX, en la ciudad se registró la cifra cercana a dieciséis mil; por este motivo se identifica a 
esta urbe como la "ciudad de los tinajones". En algún momento de este período apareció un nuevo servicio, muy popular y necesario, ya que el agua era suministrada en muchos casos por vendedores ambulantes -aguadores o aguateroscuyo negocio fluctuaba en dependencia de la abundancia o no de las lluvias (Gómez, 2009). Es importante acotar que existieron varios pozos muy conocidos como el de Bedoya, ubicado en la plazoleta que lleva su nombre, que jugaron un gran papel en esa etapa.

La ciudad se encuentra atravesada únicamente por dos ríos, los mismos que le sirvieron de cuna, el Hatibonico y el Tínima, los cuales corren de norte a sur como colectores fundamentales de las precipitaciones. Estos ríos son los encargados de acumular el escurrimiento de las aguas de sus zonas aledañas y de la ciudad en general evacuándolas al sur fuera del perímetro urbano. Sus principales dificultades son la poca capacidad de evacuación de los cauces, la sinuosidad y la presencia de escombros que obstruyen la sección del cauce, trayendo aparejadas inundaciones en períodos de intensas lluvias, agravándose por la ocupación de las márgenes. Los arroyos Méndez, Juan del Toro, El Güije y De Kilo también se encuentran sumamente contaminados.

En la actualidad, los ríos son unos de los puntos que impactan más desfavorablemente en las condiciones ambientales de toda el área de la ciudad de Camagüey, por las afectaciones por inundación al patrimonio habitacional que traen aparejado y la contaminación a la que son expuestos, debido al vertimiento hacia sus aguas de parte de los desechos del sistema de alcantarillado no concluido, constituyendo un ciclo de contaminación, no solo del manto freático, sino de las aguas superficiales.

El suministro de agua a la ciudad a través del acueducto comienza en la etapa republicana, en la cual desde 1904 empiezan a realizarse los estudios de terreno y a fabricarse los planos para la construcción de un moderno sistema de abastecimiento de agua, formado por la presa Pontezuela, una estación de bombeo, una conductora hasta un tanque elevado ubicado en la loma García y desde allí a la ciudad con una longitud total en tuberías aproximadamente de $23 \mathrm{Km}$; este conjunto podía abastecer en aquellos momentos a 45 mil personas, sin embargo por el crecimiento posterior de la ciudad y por la aparición de nuevos adelantos científico-técnicos, este recibe una serie de transformaciones.

En el período revolucionario, crece significativamente la ciudad y su población, motivado por las reformas sociales que introduce la revolución; fue necesario entonces, construir otro sistema de abastecimiento que aumentara la cantidad de agua a suministrar; esta vez desde la presa Cubano-búlgara hasta la Planta Potabilizadora con capacidad de $1200 \mathrm{~L} /$ segundo; además de éste, se construyó otro sistema de reserva desde la presa Tínima. En el 2005 se edifica desde la presa Máximo un conducto de 17 $\mathrm{Km}$ que converge con el conducto Cubano-búlgara a Camagüey. (Geocuba, 2016) (Ver Figura 6)
Figura 6. Sistema de abastecimiento de agua del municipio de Camagüey

Fuente: Elaborado por los autores a partir de revisión bibliográfica

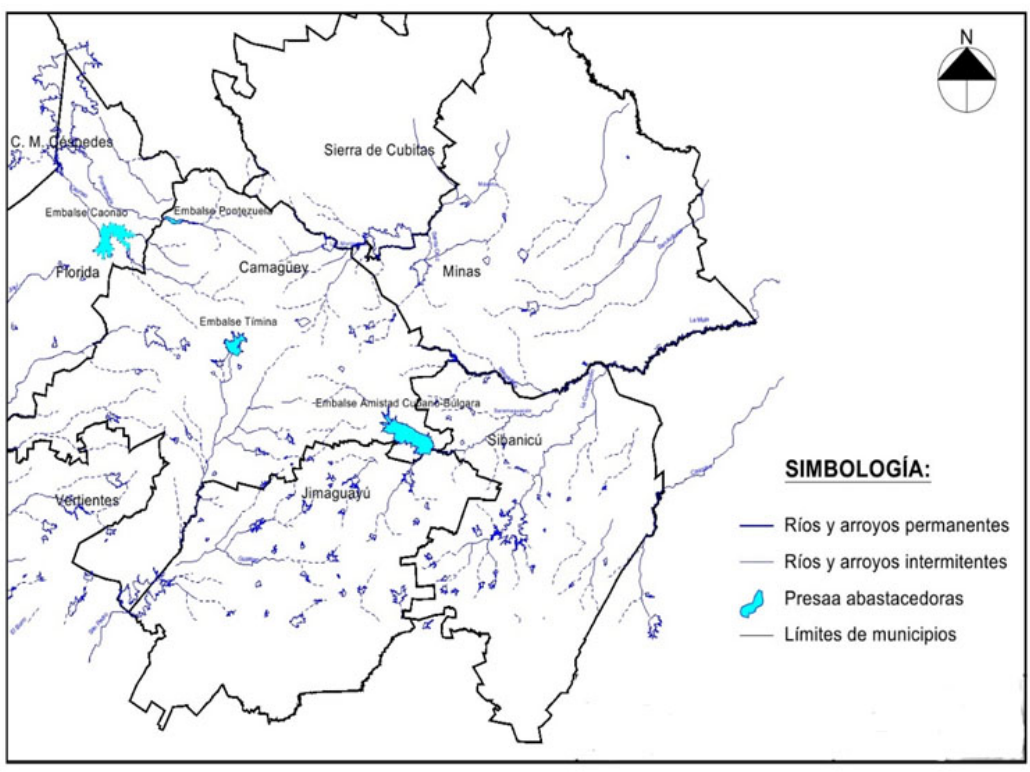


A principios del siglo $\mathrm{XX}$ se construyeron las primeras redes de abasto de agua en la ciudad. Se refiere en el Plan General de Ordenamiento Territorial que el acueducto se introdujo junto con otros avances científico- técnicos en las zonas residenciales de la ciudad republicana; y en los años 70 se manifestaba una situación crítica de las fuentes y los sistemas de abasto de agua a la población, servida por acueducto el $87.5 \%$. La población servida era el 42\% (Dirección, 2018). La siguiente tabla muestra la situación en cuanto a las aguas superficiales y a la infraestructura hidráulica tanto en el municipio, como en la provincia de Camagüey. (Ver Tabla 1)

No obstante, a los grandes esfuerzos realizados por el gobierno, solo parte de sus habitantes se beneficia, sobre todo aquellos que viven en las zonas altas o en las periferias poseen dificultades con el acceso a agua potable. (Ver Figura 7 p. 22)

En Camagüey, en el 2008, se cumplió con el acuerdo de lograr un incremento en la mejora de los indicadores de gestión de la calidad y eficiencia en los servicios de abasto de agua que permitan dar un servicio con la calidad requerida, lo que se evidenció en un abastecimiento de agua con buena calidad bacteriológica, alcanzando más del $95 \%$ de potabilidad conciliada con el MINSAP y se mantiene la condición de eficiencia en el 100\% de la infraestructura (Empresa, 2016).

El acueducto, con más de 80 años de explotación, no satisface las necesidades de toda la población, beneficiando cerca de un $75 \%$, además tiene mala calidad de agua por problemas en embalses de abasto y por el mal estado de las redes técnicas, quedando algunas zonas sin servir, al predominar en estas el consumo de agua subterránea a través de pozo.
Debido a lo anterior y al verse en la imposibilidad de acceder al agua fácilmente la población adopta medidas como la extracción del líquido con propiedades alteradas en pozos improvisados por esfuerzo propio, que no cumplen con los niveles de calidad permisibles, otra actitud perjudicial es el almacenamiento en condiciones negativas que posibilitan la contaminación y la proliferación de agentes patógenos y vectores (intermediarios en la transmisión indirecta de un agente desde un reservorio a un hospedero susceptible).

El $60 \%$ del agua bombeada para la red se pierde en salideros, otros problemas se encuentran las elevadas pérdidas en el sistema, la insuficiente capacidad de conducción, el mal estado de las acometidas intradomiciliarias, la falta de redes en algunas zonas de la ciudad, un deficiente metraje, las bajas dotaciones reales de suministro, el mal estado técnico de los equipos de bombeo, el déficit en el volumen de almacenaje de las fuentes de abasto, la carencia de equipos de mediciones en la red, para la operación del sistema y las redes de comunicaciones incompletas. Por todo lo anterior el tiempo promedio de agua para la población es de seis horas en los lugares servidos estimándose que un $60 \%$ del agua que se bombea para la red se pierde en salideros. El 7\% de los repartos de la ciudad están servidos por solución parcial, el 33\% están servidos por acueducto, el 36\% no tienen acueducto y el $24 \%$ de los repartos de la ciudad están medianamente servidos por acueducto.

El agua de abasto en la ciudad tiene mala calidad según muestran los siguientes indicadores al cierre del 2002 (Ministerio, 2018):

- Índice de cloración al $25.5 \%$ del $90 \%$ normado por la falta de un adecuado funcionamiento de la planta de tratamiento.

Tabla 1. Potencial comparativo del municipio de Camagüey

\begin{tabular}{|c|c|c|c|c|}
\hline \multicolumn{2}{|l|}{ Municipio Camagüey } & \multicolumn{2}{|l|}{ Provincia Camagüey } & \multirow[t]{2}{*}{$\%$} \\
\hline Indicador & Volumen $\left(\mathrm{Hm}^{3}\right)$ & Indicador & Volumen $\left(\mathrm{Hm}^{3}\right)^{*}$ & \\
\hline Aguas Superficiales & 280.19 & Aguas Superficiales & 3635.0 & 8 \\
\hline \multicolumn{2}{|c|}{ Infraestructura Hidráulica: } & \multicolumn{2}{|c|}{ Infraestructura Hidráulica: } & \\
\hline Presas: 3 & 259.85 & Presas:49 & 1146.4 & 23 \\
\hline Micropresas: 23 & 20.35 & Micropresas:49 & 146.4 & 14 \\
\hline $\begin{array}{l}\text { Volumen de agua } \\
\text { para el abasto a la } \\
\text { población. }\end{array}$ & 154.65 & $\begin{array}{l}\text { Volumen de agua } \\
\text { para el abasto a la } \\
\text { población. }\end{array}$ & 403.16 & 38 \\
\hline
\end{tabular}

Fuente: Elaborado por los autores a partir de revisión bibliográfica. *Hm³ representa hectómetro cúbico 
- Dosificación de cloro insuficiente en la red de distribución (trazas).

- La calidad bacteriológica por debajo de los índices normados $(58.4 \%)$.

Del total de pozos que se les realizó muestreo dentro del perímetro urbano de la ciudad (20 en total), presentan diferentes grados de contaminación 14 , para un $70 \%$.

De hecho es el recurso agua (tanto superficial como subterránea) uno de los recursos naturales más afectados como consecuencia de la contaminación con residuales líquidos; comunales e industriales, sin tratar o deficientemente tratados (sólo el $0.12 \%$ de las aguas residuales son tratadas).

A raíz de la precaria situación existente en la infraestructura hidrosanitaria fue presentado en 2014 el Proyecto Rehabilitación de suministro de agua e higienización de ciudad de Camagüey. El mismo, propone la ejecución de actividades para la mejora del sistema de acueducto $\mathrm{y}$ alcantarillado de esta ciudad, con un monto total de alcance de 92. 95 millones a propiciar por un crédito de Arabia Saudita a Cuba. Para la primera etapa del proyecto, puesta en práctica en diciembre del 2015, el Fondo Saudita para el
Desarrollo concedió 40 millones de dólares, 43\% del monto total. (Empresa, 2016)

Los especialistas decidieron no ampliar las redes, para que una vez terminada la rehabilitación, se garantice la permanencia y la cantidad de agua en los hogares y el sector estatal de la ciudad, disminuyendo las pérdidas por salideros. Por este motivo, el programa inversionista abarca, entre otras obras, la construcción de una nueva conductora en la presa Amistad Cubano-Búlgara, la rehabilitación de la planta potabilizadora de la ciudad de Camagüey, nuevos equipos en estaciones de bombeo y la reparación de redes y conductoras.

Se pudo constatar que el monto ejecutado hasta el 2017, era de aproximadamente 23 millones de dólares, correspondiendo al 57, 8\% del total. De estos, la mayor inversión fue dedicada a materiales y equipos, mientras que el resto se destinó a obras civiles para la construcción de sistemas de abastecimiento y saneamiento, y servicios de administración.

Mientras que, el servicio de alcantarillado en Camagüey colecta las aguas residuales y las dirige a desaguar en los ríos Tínima y Hatibonico exterminando formas de vida acuática e impidiendo la utilización de estas aguas para otros usos y actividades.

Figura 7. Áreas servidas por agua potable en la ciudad de Camagüey

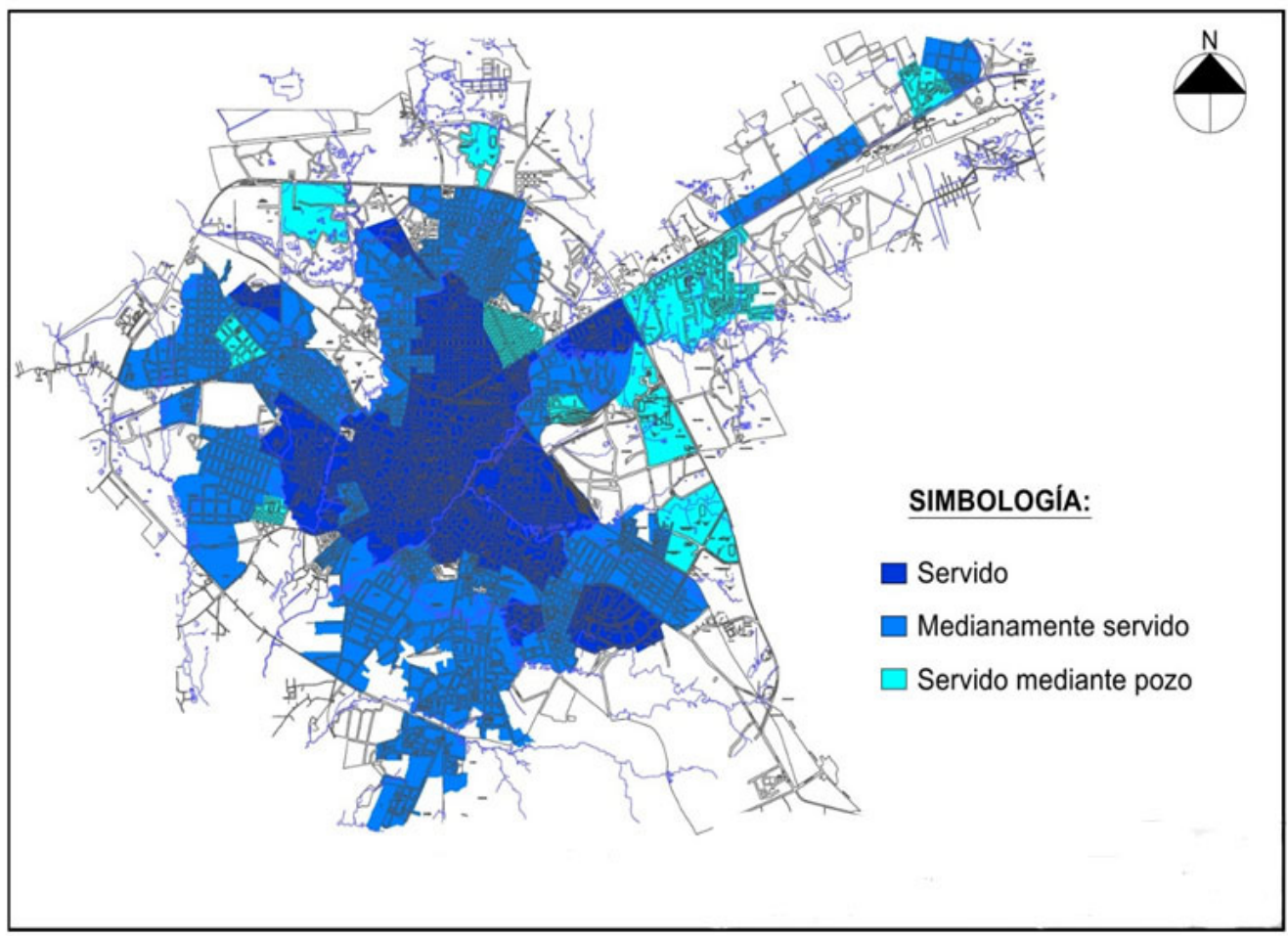

Fuente: Elaborado por los autores a partir de revisión bibliográfica 
El sistema de alcantarillado se completa con los colectores principales de residuales que evacuan los albañales hacia el sur de la ciudad. En la actualidad se encuentran construidos cinco: Marginal Hatibonico, Marginal Tínima-Méndez, Colector Juan del Toro, Marginal Este - Oeste, Colector Santa Cruz. Los grandes volúmenes de residuos que se generan en la ciudad con alta concentración de gérmenes patógenos, son unas de las principales vías de transmisión de enfermedades. La ciudad no cuenta con planta de tratamiento de residuales. Se prevé su ubicación al sur de la circunvalación en la margen izquierda del río Hatibonico.

En el presente, la población servida por la red sanitaria es el 144,755 habitantes, lo cual corresponde al $48 \%$ y representa el $40 \%$ de la superficie urbana. La carencia de alcantarillado en el $60 \%$ de área de la ciudad provoca vertimientos directos de residuales por parte de la población y otras instalaciones tanto industriales como de otro tipo en los ríos y arroyos que atraviesan la ciudad provocando un alto grado de contaminación en estos. Las zonas no servidas por el alcantarillado evacuan sus residuales mediante fosas. El 27\% de los repartos cuentan con alcantarillado y el $73 \%$ de los repartos de la ciudad no cuentan con el servicio. (Ver Figura 8)

El sistema de drenaje pluvial de la ciudad está parcialmente construido solo en el centro, en algunos repartos urbanizados y en zonas de nuevo desarrollo de edificios y viviendas. Por la falta de mantenimiento, la calidad del sistema se encuentra deteriorada, calificándose de regular y mala en los repartos donde existe, por su inadecuado funcionamiento tienen lugar inundaciones parciales ante fuertes lluvias, fundamentalmente en Montecarlo y Puerto Príncipe.

La recogida de los desechos sólidos se efectúa por distritos de forma diaria en el centro y las vías fundamentales y días alternos en los calles repartos, entidades laborales, educacionales y recreativas; oscilando entre tres y cuatro veces por semana. Se ejecuta a través de carros de combustible y de tracción animal, con una calidad entre regular y buena. De los seis vertederos dispersos en la ciudad, dos pertenecen al Consejo Popular Lenin-Albaisa (Lenin y Cabeza de Vaca), aspecto que compromete su situación higiénica.

Figura 8. Áreas servidas por alcantarillado en la ciudad de Camagüey

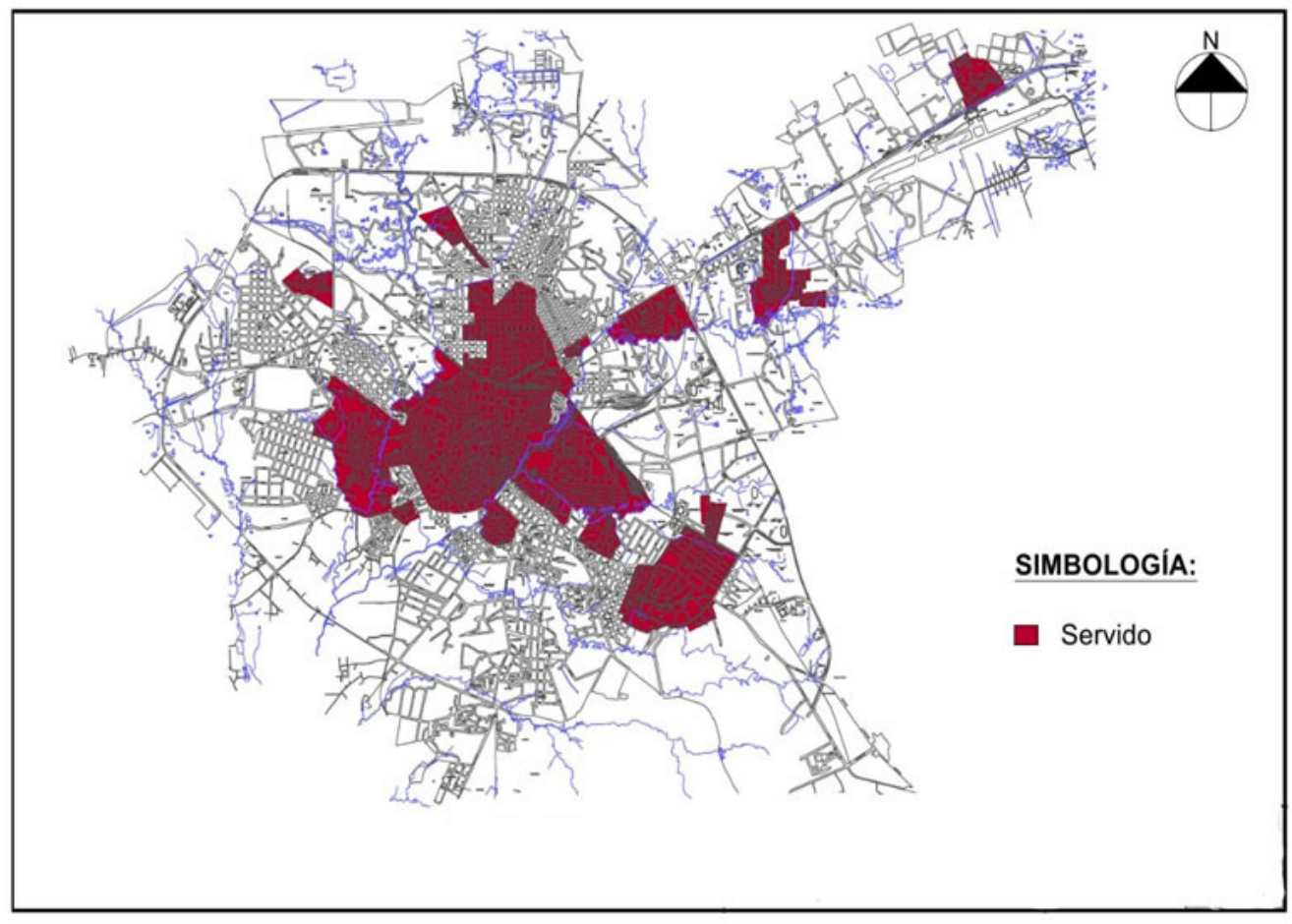

Fuente: Elaborado por los autores a partir de revisión bibliográfica 


\section{Variable salud}

La contaminación hídrica es una modificación del agua, que la vuelve impropia o peligrosa para el consumo, la industria, la agricultura, la pesca y las actividades recreativas, así como para la vida cotidiana. Es provocada por el hombre y son más vulnerables a la contaminación las aguas superficiales, pues están más en contacto con la actividad humana que las subterráneas.

Durante siglos, las aguas superficiales (ríos, arroyos y lagos) han sido usadas incorrectamente, para descargar desechos humanos e industriales, que pueden ser incluso altamente tóxicos. Los contaminantes pueden deteriorar o destruir la vida acuática, amenazar la salud humana, dañar la vida silvestre y perjudicar las operaciones industriales.

Hoy día la mayoría de los pueblos carecen de un abastecimiento adecuado de agua pura, a pesar de ser la necesidad más fundamental del hombre, por lo que, casi todos los problemas de salud derivados del agua proceden de la no separación de sus funciones principales; el agua sucia se mezcla con la pura, corriendo el riesgo la población que vive en las ciudades de enfermarse.

De forma general, las enfermedades relacionadas con el uso de agua incluyen aquellas causadas por microorganismos y sustancias químicas presentes en el agua potable; donde se calcula que la morbilidad y mortalidad se reduce entre un 20 y un $80 \%$ si se garantiza la potabilidad y adecuada canalización de las mismas en las urbanizaciones.
Por lo que resulta importante conocer, cuáles son las enfermedades de origen hídrico producidas por un mal manejo del agua potable o residual a la que se enfrentan las ciudades. Estas enfermedades, se transmiten al beber agua infectada, comer pescado y marisco contaminado, bañarse, nadar o vadear en aguas contaminadas o por insectos y caracoles acuáticos (Ver Tabla 2).

Los primeros signos de alerta de contaminación de las aguas en Camagüey están relacionados con la introducción en la villa de los primeros tinajones, que llegaron a principios del siglo XVII, para marcar para siempre el entorno camagüeyano. A mediados del siglo XVII la mayoría de las casas contaba con grandes recipientes que recogían agua de lluvia por medio de canalizaciones desde los techos. Se presume que su uso de haya generalizado para contrarrestar las sequías ocasionales y una epidemia de filariasis que se pensaba provenía del agua contaminada de los ríos y lagunas, ya que la ciudad se abastecía principalmente del río Tínima y de cuatro lagunas cercanas a la villa.

Aparejado al análisis anterior, en 1620 debido a la influencia de las fuentes contaminantes, se comprometió en gran medida la situación higiénica de la ciudad, la salud y el bienestar de sus moradores: al aparecer diferentes enfermedades de origen hídrico, que provocaron la pérdida de varias vidas humanas a sus pobladores.

Según Torres Lasqueti (Torres, 1888) de cinco médicos existentes en la villa en 1805 ,

Tabla 2. Enfermedades causadas por el agua

\begin{tabular}{|l|l|l|}
\hline \multicolumn{1}{|c|}{ Enfermedad } & \multicolumn{1}{|c|}{ Nombre Común } & \multicolumn{1}{c|}{ Agente Patógeno } \\
\hline $\begin{array}{l}\text { Enteritis } \\
\text { bacteriana }\end{array}$ & Diarrea, gastroenteritis & $\begin{array}{l}\text { Campylobacter jejuni, Escherichia } \\
\text { coli, Salmonella spp., Yersinia } \\
\text { enterocolítica }\end{array}$ \\
\hline Shigelosis & Disentería bacilar & Shigella spp. \\
\hline Cólera & Cólera & Vibrio cholerae \\
\hline Paratifoidea & Paratifoidea & Salmonella paratyphi \\
\hline Hepatitis a & Hepatitis infecciosa o ictericia & Virus de la Hepatitis A \\
\hline Poliomielitis & Polio & Poliovirus \\
\hline Diarrea viral & Diarrea & Rotavirus, agente de Norwalk \\
\hline Dengue & Fiebre quebranta huesos & Virus del dengue \\
\hline Giardiasis & Diarrea & Giardia lamblia \\
\hline Teneasis & Solitaria de la res y del cerdo & Taenia saginata y Taenia solium \\
\hline
\end{tabular}

Fuente: Elaborado por los autores a partir de revisión bibliográfica 
sólo Juan Porro y el cirujano Don Carlos Loret de Mola ejercían la profesión, pues de los tres restantes, dos estaban inhabilitados por problemas de salud y un tercero ejercía poco la facultad. En 1747, en el Hospital de San Lázaro existían doce camas y en el Hospital de mujeres fundado en 1730 , se contaba con ocho; además el Convento hospital de San Juan de Dios, fundado en 1728, para proporcionar albergue y asistencia médica a los enfermos pobres. En 1835, se produjo en la ciudad una invasión de cólera, producida por beber aguas contaminadas sus habitantes.

La cantidad de médicos y hospitales existentes en la villa antes de comenzar la guerra en 1868 , permite concluir que, aunque deficiente, la villa tenía una estructura de salud superior a periodos anteriores, pues para finales de la primera mitad del siglo XIX, contaba aproximadamente, con treinta doctores y licenciados, aumentando la capacidad de respuesta de la comunidad médica frente a las enfermedades que aparecían.

En la actualidad, el sistema de salud en la ciudad de Camagüey (Ministerio, 2018), para un mejor estudio y control, se halla subdividido en nueve áreas, las cuales garantizan la cobertura médica a la totalidad de los residentes en la ciudad y cubren toda su extensión; dividiendo el sistema de salud camagüeyano, de acuerdo a los tres distritos que conforman el Municipio Camagüey, según el Centro Nacional de Información de Ciencias Médicas en Infomed. (Ver Figura 9 y Tabla 3 p. 26)

Figura 9. Zonas de salud de la ciudad de Camagüey

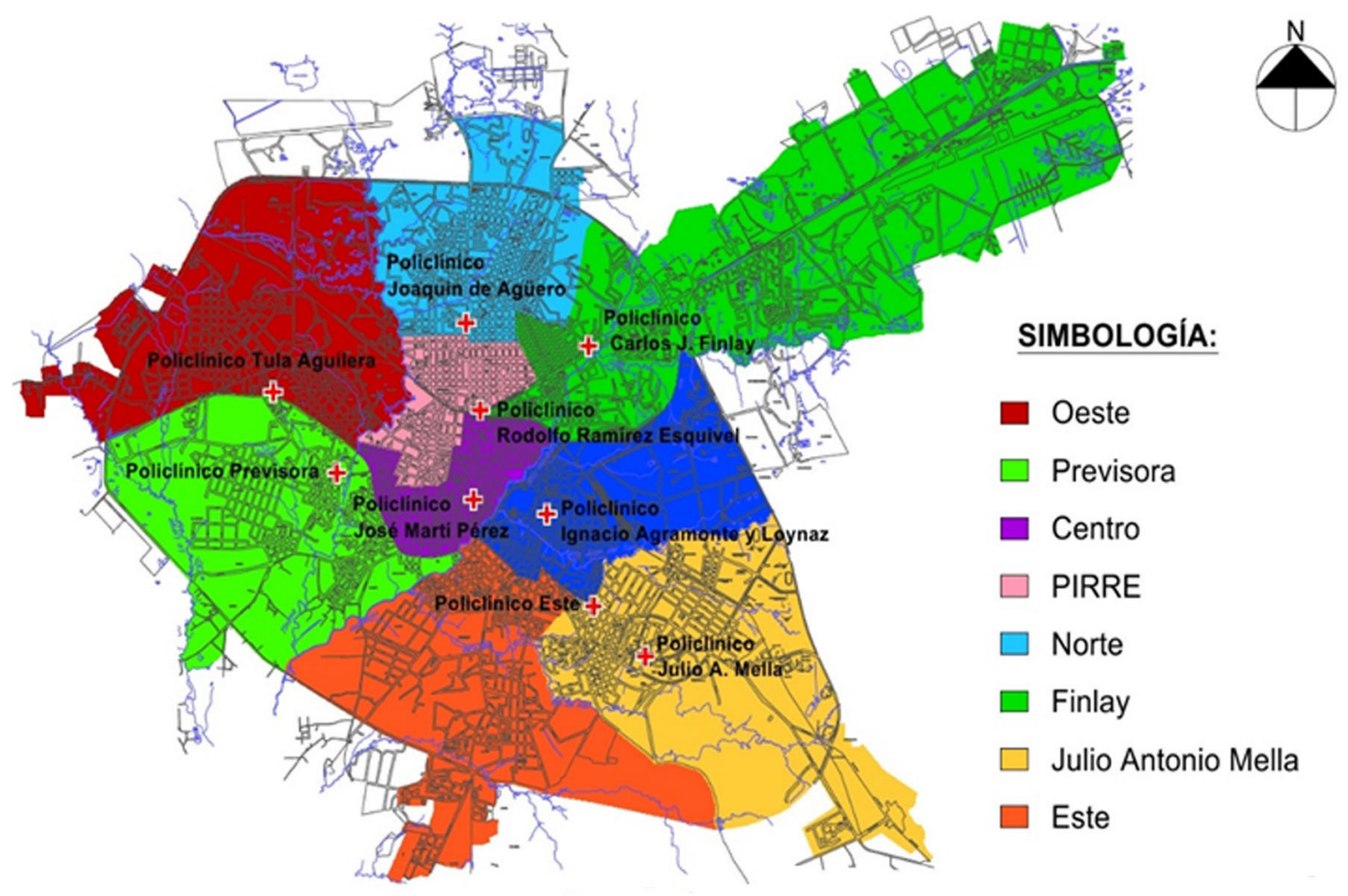

Fuente: Elaborado por los autores a partir de revisión bibliográfica 
Tabla 3. Áreas de salud

\begin{tabular}{|c|c|c|c|}
\hline $\begin{array}{l}\text { Areas de } \\
\text { Salud }\end{array}$ & Policlínico & Repartos & $\begin{array}{l}\text { Extensión } \\
\text { (ha) }\end{array}$ \\
\hline Norte & $\begin{array}{l}\text { Policlínico } \\
\text { "Joaquín Agüero } \\
\text { Agüero" }\end{array}$ & $\begin{array}{l}\text { Fraternidad, Villa Mariana, Juruquey, } \\
\text { Alturas de la Vigía, Vista Alegre, Villa Rufa, } \\
\text { Edén, Buenos Aires, Bellavista, Cándido } \\
\text { González, Van Troi, Caridad de Méndez, La } \\
\text { Vigía, Florat, } 9 \text { de Abril, Alturas del Rey }\end{array}$ & 988.08 \\
\hline PIRRE & $\begin{array}{l}\text { Policlínico } \\
\text { Rodolfo Ramírez }\end{array}$ & $\begin{array}{l}\text { La Vigía, Florat, Beneficencia, Alturas del } \\
\text { Rey, Las Mercedes, América Latina, Centro }\end{array}$ & 191.43 \\
\hline Centro & $\begin{array}{l}\text { Policlínico José } \\
\text { Martí Pérez }\end{array}$ & $\begin{array}{l}\text { América Latina, Centro, La Norma, Santa } \\
\text { Rosa, Prieto }\end{array}$ & 259.53 \\
\hline Finlay & $\begin{array}{l}\text { Policlínico "Carlos } \\
\text { J Finlay" }\end{array}$ & $\begin{array}{l}\text { Las Mercedes, José Martí, Los Ángeles, } \\
\text { Saratoga, La Arenera, Puerto Príncipe, La } \\
\text { Guernica, San Francisco, Lenin, Victoria de } \\
\text { Girón, Paco Borrero, Albaisa, Oriente }\end{array}$ & 1976.9 \\
\hline Agramonte & $\begin{array}{l}\text { Policlínico } \\
\text { "Ignacio } \\
\text { Agramonte" }\end{array}$ & $\begin{array}{l}\text { Vista Hermosa, La Caridad, Alturas del } \\
\text { Casino, Garrido, El Retiro, La Zambrana, } \\
\text { El Rastrillo }\end{array}$ & 609.26 \\
\hline $\begin{array}{l}\text { Julio } \\
\text { Antonio } \\
\text { Mella }\end{array}$ & $\begin{array}{l}\text { Policlínico "Julio } \\
\text { Antonio Mella" }\end{array}$ & $\begin{array}{l}\text { Van Horne, San Antonio, Jayamá, Alturas } \\
\text { de Jayamá, Prolongación de Jayamá, El } \\
\text { corojo, Torre Blanca, Marquezado, Salomé, } \\
\text { Julio Antonio Mella, La Esperanza, La } \\
\text { Gloria, La Nueva Esperanza, La Carbonera }\end{array}$ & 1223.0 \\
\hline Este & Policlínico Este & $\begin{array}{l}\text { La Caridad, El Retiro, Versalles, Vista } \\
\text { Hermosa, El Jardín, Barreto, José San } \\
\text { Mateo, Torre Blanca, Militar, El Diamante, } \\
\text { La Mosca, El Paraíso, La Carbonera, La } \\
\text { Yaba, La Georgina, Las Minas, } \\
\text { Prolongación de Jayamá, El corojo }\end{array}$ & 1128.3 \\
\hline Previsora & $\begin{array}{l}\text { Policlínico } \\
\text { Previsora }\end{array}$ & $\begin{array}{l}\text { Previsora, El Porvenir, Vista Bella, San } \\
\text { Miguelito, Nadales, Centro, Residencial } \\
\text { Habana, Adán, Santa Rosa, Sánchez Soto, } \\
\text { La Ceiba, Cerderias, Los Pérez, Floirán } \\
\text { Quiros, Piña, La Belén }\end{array}$ & 735.64 \\
\hline Oeste & $\begin{array}{l}\text { Policlínico "Tula } \\
\text { Aguilera" }\end{array}$ & $\begin{array}{l}\text { Imán, Tagarro, Modelo, Juanito, La } \\
\text { Mascota, Microdistrito Ignacio Agramonte, } \\
\text { La Rubia, Agramonte, Simoni, San Rafael, } \\
\text { Alturas del Cerro, Las Flores, Montejo, } \\
\text { Previsora, El Porvenir }\end{array}$ & 1261.4 \\
\hline \multicolumn{3}{|r|}{ Total } & 8373,54 \\
\hline
\end{tabular}

Fuente: Elaborado por los autores a partir de documentos del Ministerio de Salud en Camagüey 
Al realizar una caracterización epidemiológica de las enfermedades de origen hídrico, o efectos adversos del agua en la salud humana, tanto por contaminación, mal almacenamiento o escasez del agua, en la ciudad de Camagüey, se encontró que las de mayor incidencia fueron: enteritis bacteriana, giardiasis y otros parasitismos, hepatitis A, shigellosis, teniasis, el dengue y más recientemente el cólera. En octubre de 2018 se produjo un brote hídrico, de etiología biológica, que afectó a 567 personas de una comunidad perteneciente a la ciudad de Camagüey. La encuesta realizada a $409(72,1 \%)$ afectados puso de manifiesto que el $77,7 \%$ presentó diarreas. Mientras que, las 18 muestras de agua analizadas mostraron según el Método del número más probable (NMP) más de 2400 NMP de coliformes fecales; en 15 de las mismas se aisló Aeromonas hydrophila y de tres, Aeromonas jandae.

Análisis de la integración de las variables estudiadas para la ciudad de Camagüey

A modo de resumen, a pesar de todo el empeño que ha puesto el gobierno para mantener el suministro de agua adecuado, aun persisten problemas que se arrastran desde la construcción por la colonia de la ciudad, que afectan la calidad de los servicios que se prestan, entre ellos se destacan:

La contaminación del manto freático de la ciudad se inició desde la etapa colonial, por estar plagada de letrinas, iglesias donde se realizaban enterramientos, y la ubicación del cementerio general. Aspectos que perduran en la actualidad

Los ríos son unos de los puntos que impactan desfavorablemente en la contaminación de las aguas superficiales y el manto freático, debido al vertimiento de parte de los desechos de las viviendas, servicios y las industrias por no encontrarse el sistema de alcantarilla concluido y no existir planta de tratamiento; además de las afectaciones al patrimonio construido por inundaciones al estar ocupada su franja de protección por la expansión de la ciudad.

Al satisfacer el acueducto el $75 \%$ de la población de la ciudad, sus habitantes buscaron soluciones como los tinajones en sus inicios, o pozos improvisados por esfuerzo propio, que no cumplen con los niveles de calidad permisibles, $\mathrm{o}$ el almacenamiento en condiciones negativas que posibilitan la contaminación y la proliferación de agentes patógenos y vectores

El 60\% del agua bombeada para la red se pierde en salideros, otros problemas se encuentran las elevadas pérdidas en el sistema, la insuficiente capacidad de conducción, el mal estado de las acometidas intradomiciliarias, la falta de redes en algunas zonas de la ciudad, un deficiente metraje, las bajas dotaciones reales de suministro, el mal estado técnico de los equipos de bombeo, el déficit en el volumen de almacenaje de las fuentes de abasto, la carencia de equipos de mediciones en la red, para la operación del sistema y las redes de comunicaciones incompletas.

E1 27\% de los repartos de la ciudad cuentan con alcantarillado, teniendo como consecuencia vertimientos directos de residuales por parte de la población y otras instalaciones tanto industriales como de otro tipo en los ríos y arroyos que atraviesan la ciudad provocando un alto grado de contaminación en estos.

Las zonas no servidas por el alcantarillado evacuan sus residuales mediante fosas, aspecto que contamina el manto freático.

La recogida de los desechos sólidos se ejecuta a través de carros de combustible y de tracción animal, con una calidad entre regular y buena. De los seis vertederos dispersos en la ciudad, dos pertenecen al Consejo Popular Lenin-Albaisa (Lenin y Cabeza de Vaca), aspecto que compromete su situación higiénica.

Todo lo anterior posibilitó que las aguas superficiales y subterráneas de la ciudad de Camagüey se contaminaran y trajeran como consecuencia la posibilidad del riesgo a enfermarse, evidenciándose en los análisis realizados.

Posteriormente para constatar las valoraciones se solaparon la mismas a partir de los datos obtenidos del análisis de las variables: urbana, socio cultural, agua y salud en el transcurso de los años y en específico en el último quinquenio, por lo que se demuestra que las enfermedades de origen hídrico han impactado negativamente a los pobladores de la urbe principeña, fundamentalmente las enfermedades diarreicas agudas y las de origen vectorial en aquellas áreas de salud que no se encuentran servidas totalmente con el sistema de acueducto y alcantarillado o el mismo se encuentra en mal estado o contar con una densidad poblacional alta y viviendas donde se almacena el agua en recipientes no idóneos. Siendo las áreas Norte (13.82\%) y Oeste (13.54\%) las de mayor incidencia. (Ver Figura 10 p. 28) 
Figura 10. Situación sanitaria en la ciudad de Camagüey

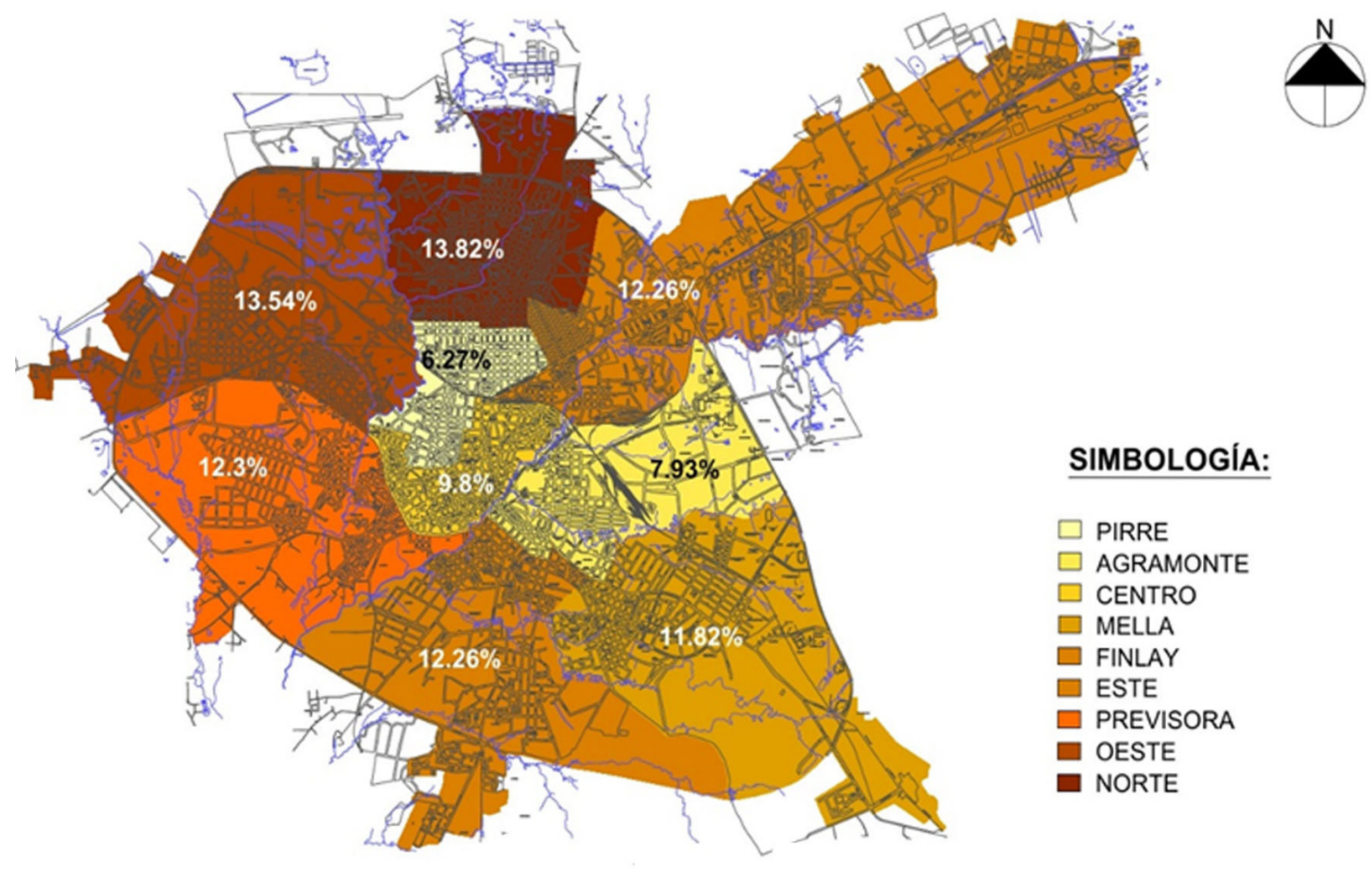

Fuente: Elaborado por los autores a partir de revisión bibliográfica

\section{CONCLUSIONES}

La ciudad, el agua y el hombre constituyen elementos que se interrelacionan en complejos procesos como un sistema, donde cada parte influye en el resto. Camagüey, ha estado siempre ligada a esta interacción, durante toda la evolución de la villa. Su expansión constante y crecimiento poblacional han traído aparejado la escasez y el uso inapropiado del recurso agua, afectándose la salud y calidad de vida de las personas.

El agua contaminada provocada por no existir infraestructura técnica completa en la ciudad, la existente estar en mal estado, la densidad poblacional que genera condiciones de insalubridad, la ocupación de las márgenes del rio y vertimiento de desechos hacia sus cause, entre otras, están relacionados con la transmisión de enfermedades como el cólera, la diarrea, la disentería, la hepatitis A, la fiebre tifoidea y la poliomielitis. Los servicios de agua y el saneamiento inexistentes, insuficientes o gestionados inapropiadamente exponen a la población a riesgos para su salud que pueden prevenirse.

Se obtuvo como resultado de la valoración entre variables que aquellas zonas con problemas de infraestructura de acueducto y alcantarillado de la ciudad de Camagüey, son en las que han incidido e en los últimos años las enfermedades de origen hídrico, fundamentalmente las diarreicas agudas y las de origen vectorial, han impactado negativamente a sus pobladores; las áreas Norte y Oeste son las más perjudicadas.

Algunos de los grandes desafíos para garantizar la calidad del agua son prevenir la contaminación desde el punto de captación hasta las redes de las viviendas, realizar el tratamiento adecuado de las fuentes de abasto, caracterizar adecuadamente las cuencas hidrográficas y realizar un análisis integrado de la vulnerabilidad de las cuencas hidrográficas y del ecosistema. Esto no solo contribuirá a reducir las enfermedades, sino los costos relacionados con la gestión de la calidad del agua. $\mathbf{C}$

\section{REFERENCIAS BIBLIOGRÁFICAS}

Acosta, R. J., y González, R. (2016). Patrimonio y contaminación: un desafío para el uso del agua. Centro histórico de Camagüey. 
Ponencia presentada en el X Simposio Internacional Desafio en el Manejo y Gestión de Ciudades, Camagüey, Cuba.

Cuellar, L; Maldonado, G. y Cepeda, Y. (2017). "Calidad del agua para el consumo humano". Revista cubana de Higiene y Epidemiología. Vol. 55, núm. 1, enero-abril, ISSN 1561-3003, pp 13-18. Disponible en: http://www.revepidemiologia.sld.cu/ index.php/hie/article/view/75/149.

Dirección Provincial de Planificación Física. (2018). Plan General de Ordenamiento Territorial y Urbanismo. Municipio Camagüey. Camagüey, DPPF.

Ecofluidos Ingenieros S.A. (2017). Estudio de la calidad de fuentes utilizadas para consumo humano y plan de mitigación por contaminación por uso doméstico y agroquímicos en Apurimac y Cusco. [Informe Final], Lima, Ecofluidos.

Empresa de Acueducto y Alcantarillado. (2016). Objetivos de trabajo de la Empresa de Acueducto y alcantarillado de Camagüey. Camagüey, Empresa.

Geocuba. (2016). Taller sobre Aguas subterráneas y Contaminación. Hacia el uso sostenible del agua en Cuba. La Habana, Geología.

Gómez, L. (2009). Camagüey y Ciego de Ávila, Guía de Arquitectura y Paisaje. Camagüey, Sevilla-Camagüey.

Gómez, L., Más V. y Prieto, O. (2006). Camagüey: ciudad y arquitectura (15141950). Camagüey, Ácana.

González, R. (2014). "Modelo de estructuración territorial de servicios y su contribución al desarrollo local". Arquitectura y Urbanismo. Vol. 33, núm. 1, eneroabril, ISSN 1815-5898, pp 43-63. Disponible en: http://scielo.sld.cu/scielo. php? script $=$ sci_arttext\&pid $=$ S 1815 $58982012000100004 \& \operatorname{lng}=$ es\&tlng=es.

Martínez, Y. (2008). Propuesta para favorecer la eficiencia y eficacia en el tratamiento de las aguas residuales con contenido de cromo hexavalente [Trabajo de grado, Ingeniería Química]. Camagüey, Universidad de Camagüey.

Mateo, J. M. (2015). La sostenibilidad del desarrollo territorial. Experiencias de Cuba y el sur de México. La Habana, Dirección de Publicaciones Académicas, Universidad de La Habana.
Ministerio de Salud Pública. (2018). Dirección Nacional de Vigilancia y Lucha Antivectorial. Vigilancia y Control del Aedes Aegypti. Camagüey, Área de Higiene, Epidemiologia y Microbiología.

Oficina Nacional de Estadística. (2013). Anuario estadístico de Cuba. La Habana, Cuba.

ONU. (2015). " $2^{\circ}$ Informe de Naciones Unidas sobre Desarrollo de Recursos Hídricos en el Mundo". [en línea]. (30 de junio 2019). Disponible en: http://www.unesco. org/new/es/natural-sciences/environment/ water/wwap/wwdr/.

Organización Mundial de la Salud. (2014). "Guías para la calidad del agua potable. Ginebra 2004". Vol.1, núm. 3, 3 de febrero 2018. [en línea]. (3 de febrero 2018). Disponible en: https://www.who.int/water_sanitation health/dwq/gdwq3sp.pdf.

Programa de Naciones Unidas para el Desarrollo. (2014). "Estado de las ciudades de América Latina y el Caribe 2012: Rumbo a una nueva transición urbana". [en línea]. (15 de diciembre 2017). Disponible en: http:// www.unhabitatworld.com.

Torres, J. (1888). Colección de Datos Históricosgeográficos y Estadísticos de Puerto Príncipe y su Jurisdicción. Ciudad de Camagüey, Editorial Científico Técnica.

Raffino, M. E. (2020). "Concepto de agua". [en línea]. (08 de junio 2019). Disponible en: https://concepto.de/agua/. 